\title{
Ultra-High Pressure Driver and Nozzle Survivability in the RDHWT/MARIAH II Hypersonic Wind Tunnel
}

\author{
M. Costantino, G. Brown, K. Raman, R. Miles and J. \\ Felderman
}

This article was submitted to

$21^{\text {st }}$ American Institute of Aeronautics and Astronautics Advanced Measurement Technology and Ground Testing Conference Denver, CO

June 19-22, 2000

U.S. Department of Energy

Lawrence

Livermore

National

Laboratory

June 2, 2000 


\section{DISCLAIMER}

This document was prepared as an account of work sponsored by an agency of the United States Government. Neither the United States Government nor the University of California nor any of their employees, makes any warranty, express or implied, or assumes any legal liability or responsibility for the accuracy, completeness, or usefulness of any information, apparatus, product, or process disclosed, or represents that its use would not infringe privately owned rights. Reference herein to any specific commercial product, process, or service by trade name, trademark, manufacturer, or otherwise, does not necessarily constitute or imply its endorsement, recommendation, or favoring by the United States Government or the University of California. The views and opinions of authors expressed herein do not necessarily state or reflect those of the United States Government or the University of California, and shall not be used for advertising or product endorsement purposes.

This is a preprint of a paper intended for publication in a journal or proceedings. Since changes may be made before publication, this preprint is made available with the understanding that it will not be cited or reproduced without the permission of the author.

This report has been reproduced directly from the best available copy.

Available to DOE and DOE contractors from the

Office of Scientific and Technical Information

P.O. Box 62, Oak Ridge, TN 37831

Prices available from (423) 576-8401

http:/ / apollo.osti.gov/bridge/

Available to the public from the National Technical Information Service

U.S. Department of Commerce 5285 Port Royal Rd., Springfield, VA 22161 http://www.ntis.gov/

OR

Lawrence Livermore National Laboratory Technical Information Department's Digital Library http://www.llnl.gov/tid/Library.html 


\section{ULTRA-HIGH PRESSURE DRIVER AND NOZZLE SURVIVABILITY IN THE RDHWT/MARIAH}

\section{PROGRAM MEDIUM SCALE HYPERSONIC WIND TUNNEL}

Marc Costantino, Lawrence Livermore National Laboratory, Livermore, CA; G. Brown, K. Raman, and R. Miles, Princeton University, Princeton, NJ; and J. Felderman, Sverdrup Technology, Inc. AEDC, Arnold AFB, TN

ABSTRACT. An ultra-high pressure device provides a high enthalpy $(>2500 \mathrm{~kJ} / \mathrm{kg}$ ), low entropy $(<5 \mathrm{~kJ} / \mathrm{kg}-\mathrm{K})$ air source for the RDHWT/MARIAH II Program Medium Scale Hypersonic Wind Tunnel. The design uses stagnation conditions of $2300 \mathrm{MPa}(330,000 \mathrm{Psi})$ and $750 \mathrm{~K}\left(900^{\circ} \mathrm{F}\right)$ in a radial configuration of intensifiers around an axial manifold to deliver pure air at $100 \mathrm{~kg} / \mathrm{s} \mathrm{mass}$ flow rates for run times suitable for aerodynamic, combustion, and test and evaluation applications. Helium injection upstream of the nozzle throat reduces the throat wall recovery temperature to about $1200 \mathrm{~K}$ and reduces the oxygen concentration at the nozzle wall.

\section{INTRODUCTION}

The Radiatively Driven Hypersonic Wind Tunnel/Magnetohydrodynamic Accelerator Research into Advanced Hypersonics (RDHWT/MARIAH II) Program design concept for the Medium Scale Hypersonic Wind Tunnel (MSHWT) is comprised of four major subsystems: 1) the ultra-high pressure (UHP) air source, 2) the energy addition source, 3 ) the magnetohydrodynamic (MHD) energy addition section, and 4) the test section.

The general background of the RDHWT/ MARIAH II Program and a systems overview are described in Best, et al. ${ }^{1}$ and Ring, et al.. ${ }^{2}$ The performance goal for the MSHWT for airbreathing propulsion testing is to achieve a Mach number, pressure, and temperature condition in the test section corresponding to conditions upstream of the in-flight scramjet forebody. This extreme test condition corresponds to a free stream Mach number of 15 and a dynamic pressure of $2000 \mathrm{lbf} / \mathrm{ft}^{2}$ at an altitude of $34.4 \mathrm{~km}$. Approximating the actual bow shock as a shock attached to a wedge with a five degree half angle results in post bow shock conditions of $2898 \mathrm{~Pa}, 408 \mathrm{~K}$, and Mach 11.3.

This article is a description of the UHP air source and the expansion nozzle section that couples the air source to the downstream nozzle section.

\subsection{System requirements}

The air source for the hypersonic wind tunnel is one of the three major subsystems that must be integrated to meet nominal system performance requirements:

- Mach Number 8-15

- Pure air

- Dynamic pressure: $500-2000 \mathrm{lbf} / \mathrm{ft}^{2}$

- Operational time: $1-100$ seconds

- Air mass flow rate: $1-100 \mathrm{~kg} / \mathrm{s}$

- Total enthalpy: $10^{7} \mathrm{~J} / \mathrm{kg}$

- Flow quality: $\Delta \mathrm{P} / \mathrm{P}<0.05$

Of the various methods of producing high enthalpy air flows, such as explosive jets, ballistic compression, and arc heating; exhaust from a static, large volume high pressure container appears to offer the lowest risk approach. Total mass (run time $x$ mass flow rate) and air chemistry $\left(\mathrm{T}_{0}<\sim 3000 \mathrm{~K}\right)$ are the primary discriminators leading to this conclusion. As an additional benefit, the high enthalpy in static air at very high pressures and moderate $(<\sim 1000 \mathrm{~K})$ temperatures is gained at a relatively low entropy. This permits relatively more entropy to be added in the energy addition region without exceeding the desired entropy at the test article. A further advantage of this approach is that a variety of end states is accessible, since the stagnation pressure and temperature can be varied continuously within 
the design envelope of the high pressure container.

\subsection{High pressure container requirements}

The nominal requirements for the high pressure container arise principally from two sources: total air mass and stagnation entropy. The total air mass depends not only on the desired Mach number, the dynamic pressure, and the tunnel cross section at the test article, but also on the details of the physics and engineering in the energy addition region. Matching the stagnation entropy to the entropy increase for specific cases of e-beam/laser/MHD energy addition results in a design curve for possible pressure-temperature (P-T) stagnation conditions. ${ }^{2}$ Generally, movement to higher pressure and lower temperature is desirable to decrease the total high pressure storage volume and to minimize the entropy while maintaining adequately high enthalpy. These considerations lead to a picture of a high pressure container with a volume of the order of 10-100 liters that operates at pressures greater than $2000 \mathrm{MPa}(0.1 \mathrm{MPa}=$ $1 \mathrm{bar} \approx 1 \mathrm{~atm}$, so $2000 \mathrm{MPa} \approx 20,000 \mathrm{~atm} \approx$ $300,000 \mathrm{Psi})$ at an air temperature above $700 \mathrm{~K}\left(430^{\circ} \mathrm{C}, 800^{\circ} \mathrm{F}\right)$. The combined pressure and temperature conditions are unusual, but are demonstrated UHP technologies. The required volume at these conditions, however, is about 2-3 orders of magnitude larger than existing devices.

\subsection{Nozzle requirements}

In the P-T regimes of interest to the UHP subsystem, air is a real gas: at $2300 \mathrm{MPa}$, $750 \mathrm{~K}$ the compressibility factor, $Z=8.9$. The unit Reynolds number for flows relevant to this problem is of the order of $10^{10} \mathrm{~m}^{-1}$. The real gas recovery temperature in the boundary layer is much higher than the stagnation temperature, the value it would have for an ideal gas flow. As an example, air at a stagnation temperature of $750 \mathrm{~K}$ and pressure $2300 \mathrm{MPa}$, for the nominal nozzle dimensions under consideration here, has a recovery temperature at the nozzle throat of about $1700 \mathrm{~K}$, compared to an ideal gas recovery temperature of $750 \mathrm{~K}$. The axisymmetric nozzle, for the range of conditions described above, has a throat di- ameter of 3-10 $\mathrm{mm}$ and a precise profile and high surface smoothness for a downstream distance of $10-20 \mathrm{~cm}$. Finding a material with the combination of strength and oxidation chemistry properties required to sustain this insult presents a challenge.

\subsection{Mechanical and operational integration}

Mechanical integration of the air source with the downstream elements of the wind tunnel provides its own set of requirements. In the presently selected energy addition scheme, $\mathrm{O}(100 \mathrm{MW})$ of e-beam energy is added to the supersonic flow within a downstream distance of about $10 \mathrm{~cm}$ of the nozzle throat. The electrons are focused into the core of the flow using a solenoidal magnetic field having a field strength $\mathrm{O}(7 \mathrm{~T})$. This means the nozzle at and just upstream of the throat, which must contain the air at about the stagnation conditions, also must fit inside the aperture of a high performance magnet and be compatible with the strength and timing of the magnetic field.

Operational times for steady flow may vary from a few tenths of a second for aerodynamic testing to a few seconds for combustion testing to $100 \mathrm{~s}$ of seconds for component survivability testing. Synchronization of the air flow with the energy addition and the data collection at the test article is a critical concern in avoiding damage to the air source, the e-beam source, or the test article. Means of generating, storing, and releasing the UHP air reproducibly and in a controlled way present additional challenges in the UHP subsystem design. The design goal is to control the transient from one stagnation pressure to another over the time scale of $0.1-0.5 \mathrm{~s}$ and to maintain the stagnation pressure constant to within $5 \%$ during the "steady flow" portion of the experiment.

It is highly likely that the nozzle and other expendable components, such as moving UHP seals, of the UHP subsystem will require frequent inspection and replacement. The component, people, and time costs to perform this maintenance should be commensurate to the operational costs of the other subsystems. Practically, this means providing easy accessibility to the nozzle and the high pressure seals. It also leads to a cost-driven design for com- 
ponents that must be replaced periodically because of fatigue or excessive plastic flow.

Finally, testing requires a variety of diagnostics, many of which must be integrated into the UHP air source. These diagnostics must be robust enough to survive the extreme pressure, temperature, and electromagnetic conditions in the nozzle and, at the same time, permit convenient and inexpensive calibration.

\subsection{Previous work}

Existing hypersonic facilities ${ }^{3,4}$ generally fail to meet the run duration, mass flow rate, and air flow chemistry requirements for fullservice hypersonic testing. The facility most relevant to our approach was designed during the early 1970 s by Meshcheryakov, et $a l^{5}$ at the Institute of Hydrodynamics and the Design and Technology Institute of High Rate Hydrodynamics in Novosibirsk. Their device, which they named the "A-1," was intended to provide a $100 \mathrm{~ms}$ flow of air at stagnation conditions of $1500 \mathrm{MPa}$ and $2000 \mathrm{~K}$. Owing to nozzle survivability issues, the maximum operating parameters have been $(930 \mathrm{MPa}$, $1795 \mathrm{~K}$ ) in nitrogen using a tungsten carbide nozzle and $600 \mathrm{MPa}$ in air using a copper composite. ${ }^{6-7}$

Their ingenious approach incorporated many UHP techniques to solve a very difficult design problem. An operating gas at low pressure $(1-10 \mathrm{MPa})$ is compressed quasiadiabatically to a few hundred MPa using an auxiliary ballistic piston and then injected into the main pressure chamber having a volume of the order of $40 \mathrm{~cm}^{3}$. The final compression to the stagnation condition is provided by a standard pressure "intensifier," in which a (relatively) low pressure fluid acting over a large diameter of a piston is used to increase the pressure of the operating gas acting over a small diameter piston. Their design used a variable radial supporting stress to manage the radial deformation of the pressure vessel bore, thus avoiding a moving seal at the high pressure end of the piston. The rapid prepressurization and synchronous final pressurization permitted a steady flow over $0.1 \mathrm{~s}$ without a valve at the nozzle throat. Finally, the apparatus was designed so that the momenta of the various moving parts cancelled, resulting in displacements of the apparatus of about $0.25 \mathrm{~mm}$.

The limitations of this scheme are total mass of the operating gas and nozzle survivability. The design can be expanded to volumes permitting about one second of flow. However, the adiabatic compression path results in stagnation temperatures too high for existing nozzle materials and stagnation entropies too high for the subsequent radiant en-

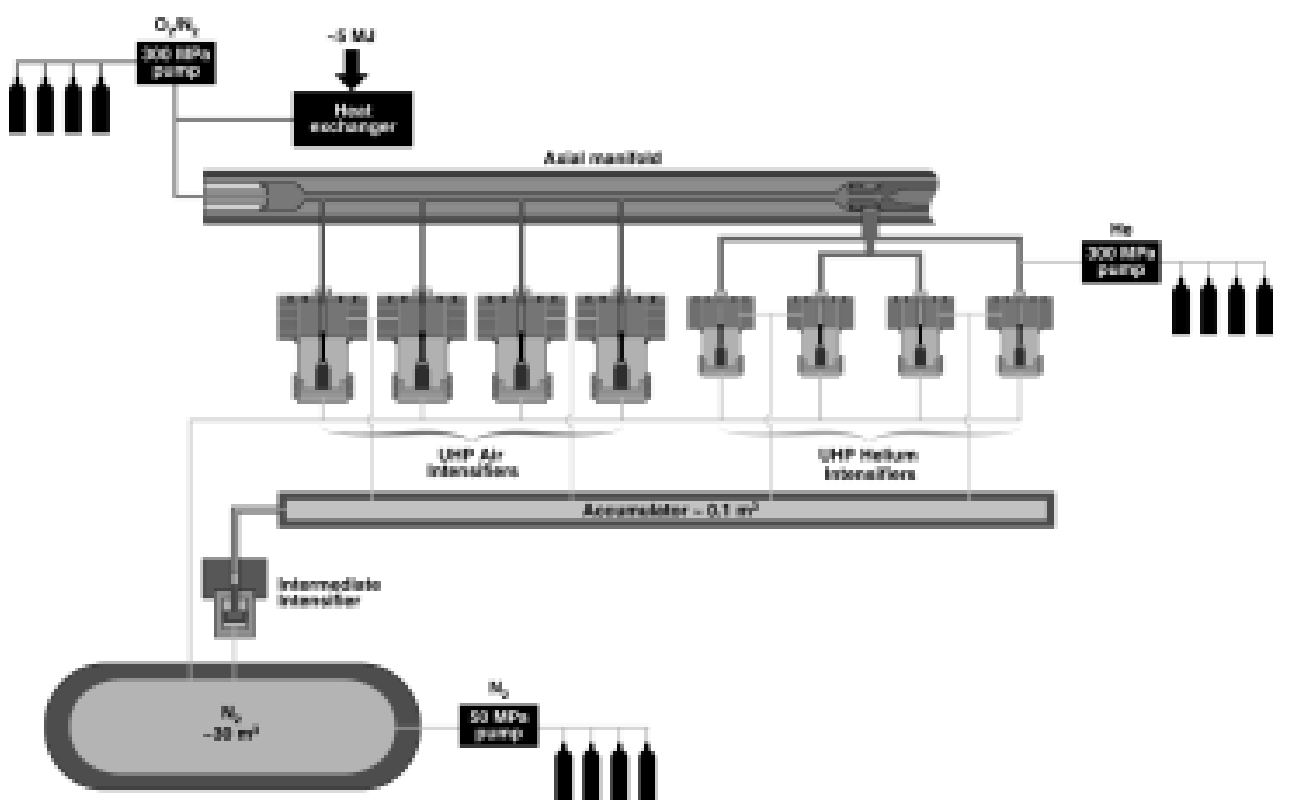

Figure 1. Schematic of the UHP driver for the RDHWT/MARIAH II wind tunnel. Energy is stored in the low pressure nitrogen that drives the 100:1 area ratio intensifiers to generate air pressure 100 times the nitrogen pressure. The helium intensifiers inject helium into the boundary layer immediately upstream of the nozzle throat. $\mathrm{In}^{3}$ operation, the intensifiers are arrayed radially 
ergy addition to the test condition.

\subsection{MSHWT approach}

The remainder of this article is a description of a design approach that builds on the "A-1" concept to meet the MSHWT system requirements. The design concept provides for an arbitrarily large volume of air at pressures up to $2500 \mathrm{MPa}$ at temperatures up to $750 \mathrm{~K}$. We assume the nozzle wall must be protected by a film of helium both to reduce the wall temperature and to decrease the oxygen concentration at the wall. State-of-the-art finite element analysis (FEA) of proven high pressure engineering configurations using commercially available materials reduce the design risk. The UHP subsystem, termed the "A-2," has a stagnation condition design point of $2300 \mathrm{MPa}$ and $750 \mathrm{~K}$ in air to provide a flow of $10 \mathrm{~kg} / \mathrm{s}$ for $1 \mathrm{~s}$. The following three sections are a description of the UHP subsystem design, the nozzle, and an experimental plan for nozzle development and component testing.

\section{ULTRA-HIGH PRESSURE SUBSYSTEM}

\subsection{Overview}

The UHP subsystem ${ }^{8}$ is comprised of five major elements: 1) a large volume $\left(\sim 30 \mathrm{~m}^{3}\right)$, low pressure $(40 \mathrm{MPa}, 6000 \mathrm{Psi})$ nitrogen source to drive the UHP intensifiers, 2) an axial manifold to connect the UHP intensifier volumes, 3 ) radially arrayed air intensifiers to provide the air flow, 4) radially arrayed helium intensifiers to provide a boundary layer cooling film, and 5) reaction load frames to contain the pressure-induced loads. Figure 1 is a schematic of the subsystem. The air intensifiers are arranged in at least four-fold radial symmetry around an axial manifold. A single array of four intensifiers is adequate for a flow of $10 \mathrm{~kg} / \mathrm{s}$ for $1 \mathrm{~s}$. Total volume of the system is adjusted by adding layers of these radial arrays to the axial manifold. The helium intensifiers inject a cooling film into the boundary layer immediately upstream of the nozzle throat. A single radial array is adequate for run times of the order of a few seconds. For longer run times, helium is injected through its own 4-fold symmetric radially arrayed axial manifolds, with each manifold connected to radial arrays of helium intensifiers. External reaction frames contain a force of $\mathrm{O}\left(10^{7} \mathrm{~N}\right)$ $\left(5\left(10^{6}\right) \mathrm{lbf}, 2400\right.$ tons $)$ produced by a maximum of $2700 \mathrm{MPa}$ acting over a piston diameter of $10 \mathrm{~cm}$.

In operation, the working gas in the UHP intensifier (Figure 2) is pre-pressurized and heated to bring the gas to an entropy equal to the entropy at the operating stagnation pressure and temperature. Typical values for this state are $300 \mathrm{MPa}$ and $450 \mathrm{~K}$. The resulting substantial decrease in the compressibility also reduces the piston stroke required to reach the stagnation pressure, which is important to the length/diameter ratio of the piston that must carry the full pressure as a uniaxial stress. Over a time of about $0.5 \mathrm{~s}$, low pressure nitrogen or an intermediate pressure fluid is introduced at a controlled mass flow rate into the low pressure end of the intensifier. This causes the intensifier piston to move, reducing the volume of the plenum and increasing the pressure to provide the desired pressure vs. time profile. A valve at the nozzle opens at a pre-determined time to initiate the flow. At the end of the flow, the low pressure nitrogen or fluid is vented, causing the piston to stop.

\subsection{UHP Intensifier}

The target condition for an A-2 UHP intensifier (Figure 2) is $2300 \mathrm{MPa}$ at $750 \mathrm{~K}$ at a volume of 21 . An operating pressure of $2300 \mathrm{MPa}$ implies a proof pressure of about

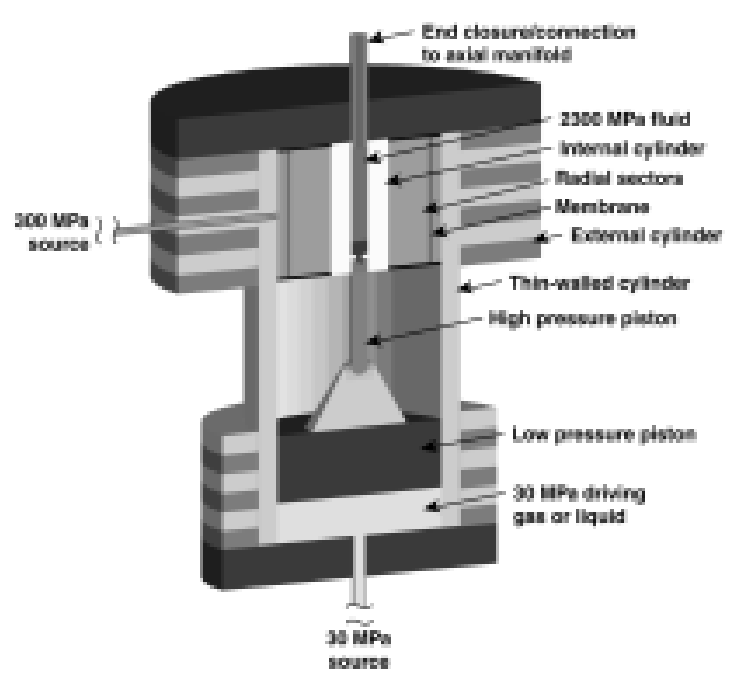


$2700 \mathrm{MPa}$ (391,000 Psi), which exceeds the room temperature yield strength of even the highest performing steels. Further, a gas temperature of $750 \mathrm{~K}\left(900^{\circ} \mathrm{F}\right)$ results in a decrease in mechanical properties of the metal near the bore of the pressure vessel by as much as $30 \%$. These conditions demand design approaches that provide an external, inwardly acting radial mechanical stress to add to the inwardly acting thermal stress and the outwardly acting radial stress owing to the pressure. While there are several methods to do this, the compound cylinder and the radial sector designs are applicable to this problem. ${ }^{9}$ The compound cylinder provides a constant compressive radial stress by means of shrink-fitting cylindrical layers. The design typically is limited by the compressive strength of the innermost layer material and by the requirement for a moving ultra-high pressure seal having a deformable packing to accommodate the expansion of the vessel bore with respect to the UHP piston. Fabrication and operational costs are significantly less than for the radial sector approach.

In the radial sector approach the deformation of the bore of the vessel is controlled by means of a variable external radial stress provided by sectors loaded on their outer boundaries by an auxiliary high pressure fluid. This variable radial support scheme at once provides for elastic operation of the vessel and a controlled clearance between the UHP piston and the vessel bore. This approach must be used when the yield strength of the vessel material is inadequate to contain the pressure and when the gap between the UHP piston and the vessel bore must be controlled. Fabrication and operation costs for the radial sector design are significantly higher than for the compound cylinder. The radial sector design provides a significantly larger pressure-temperature operational envelope than the compound cylinder.

The radial sector intensifier consists of a relatively thin-walled liner of high strength, oxidation resistant steel, such as a maraging steel with a room temperature yield strength of $2400 \mathrm{MPa}$. At $750 \mathrm{~K}$ the strength is about $75 \%$ of the room temperature value and the elastic modulus about $85 \%$. The liner is supported by a radial array of sectors which, for this application, are made of a layer of tungsten carbide supported by a layer of AISI 4340 steel. Fluid pressure, approximately $1 / 10^{\text {th }}$ the operating gas pressure, is applied to the outer surface of the sectors through a thin $(5 \mathrm{~mm})$ steel membrane. This pressure is contained in an outer pressure vessel of AISI 4340 steel. The overall diameter of the intensifier is about $1800 \mathrm{~mm}$ and the overall length of the UHP end about $1000 \mathrm{~mm}$.

The UHP intensifier piston is comprised of an ultra-high pressure, small diameter section and a low pressure, large diameter section. Since the UHP section must carry the pressure as a uniaxial stress, it is made of a high strength tool steel or tungsten carbide. The pressure seal design at the UHP section depends upon the survivability of seal packing materials at operating temperatures. The lowest risk seal is a Bridgman unsupported area design, which requires a relatively weak packing that must sustain heat flow from the operating gas and from friction. Polytetrafluoroethylene (Teflon ${ }^{\circledR}$ ) works to about $550 \mathrm{~K}$, while a polyimide (Vespel@) survives to about $750 \mathrm{~K}$. A controlled clearance seal is required for operating conditions for which there are no suitable packing materials. In this seal, the relative radial displacements of the bore of the pressure vessel and the UHP piston are managed so that the leak rate through the gap is acceptable.

The force balance between a low pressure fluid acting over a large area and a high pressure fluid acting over a small area provides the pressure "intensification." For the A-2 device, the pressure in the nitrogen driving gas is set by the area ratio of the high pressure to low pressure ends of the intensifier piston: $\mathrm{P}_{\mathrm{N} 2}=$ $\left(A_{\text {high }} / A_{\text {low }}\right) P_{\text {air }}$, where $A_{\text {high }} / A_{\text {low }} \sim 1 / 100$. For a proof pressure of $2700 \mathrm{MPa}$, the driving pressure is $\sim 30 \mathrm{MPa}$, owing to various frictional forces in the system.

\subsection{Axial manifold}

An axial manifold connects the UHP intensifier volumes to each other and to the nozzle. The manifold (nominally $1 \mathrm{~cm}$ ID and $20 \mathrm{~cm}$ OD and $3 \mathrm{~m}$ long) is a compound cylinder. The ID is defined by the mass flow rate out of the throat and requiring the flow speed of the $2300 \mathrm{MPa}$ air in the manifold to be low enough not to introduce undesired fluid dynamics effects (nominally < Mach 0.2 ). The length of this manifold can be increased as re- 
quired by joining similar sections. One end of the manifold accommodates the various highpressure feedthroughs required for diagnostics (thermocouples and pressure gauges), prepressurization gas input, and mechanical motion couplings (as may be required for an internal valve). The other end accommodates the nozzle assembly. To provide the area for the various axial penetrations through the end closure, the internal diameter of the section of the manifold at its ends is expanded to about $10 \mathrm{~cm}$.

Stress concentrations at the crossbores connecting the radially arrayed UHP intensifiers to the axial manifold may be as much as a factor of six with respect to the internal pressure. Although these stresses result in only local regions of plastic flow, surrounded by significant elastic regions, the fatigue life of the manifold can be extended by decreasing the local stresses at the intersection of the crossbore with the axial bore. This is accomplished by applying an external compressive radial stress to the crossbore region using the end closures of the UHP intensifiers, as shown in Figure 3.

\subsection{Cooling film injection}

The recovery temperature at the nozzle throat for a pure air flow at the design point is about $1700 \mathrm{~K}$ and the oxygen fugacity is about twelve times the pressure. Although the surface of the candidate nozzle materials is passivated by $\mathrm{Cr}_{2} \mathrm{O}_{3}$, the combination of the high temperature, high oxygen fugacity, and a probable ignition source (such as interaction between the e-beam and the wall), likely will result in combustion of the nozzle material. Helium injected into the boundary layer immediately upstream of the nozzle throat displaces the air in the boundary layer, cools the nozzle wall, and results in a lower recovery temperature downstream. For helium injected at the Mach 0.5 point (at a pressure of about $1700 \mathrm{MPa}$ ) in the air core flow, the helium recovery temperature at the throat is about $1200 \mathrm{~K}$. Mass and thermal transport across the boundary layer are under investigation.

A radial array of intensifiers, similar to those providing the UHP air, provides the variable external radial stress supporting the nozzle region as well as the helium that is injected into the boundary layer. The proximity

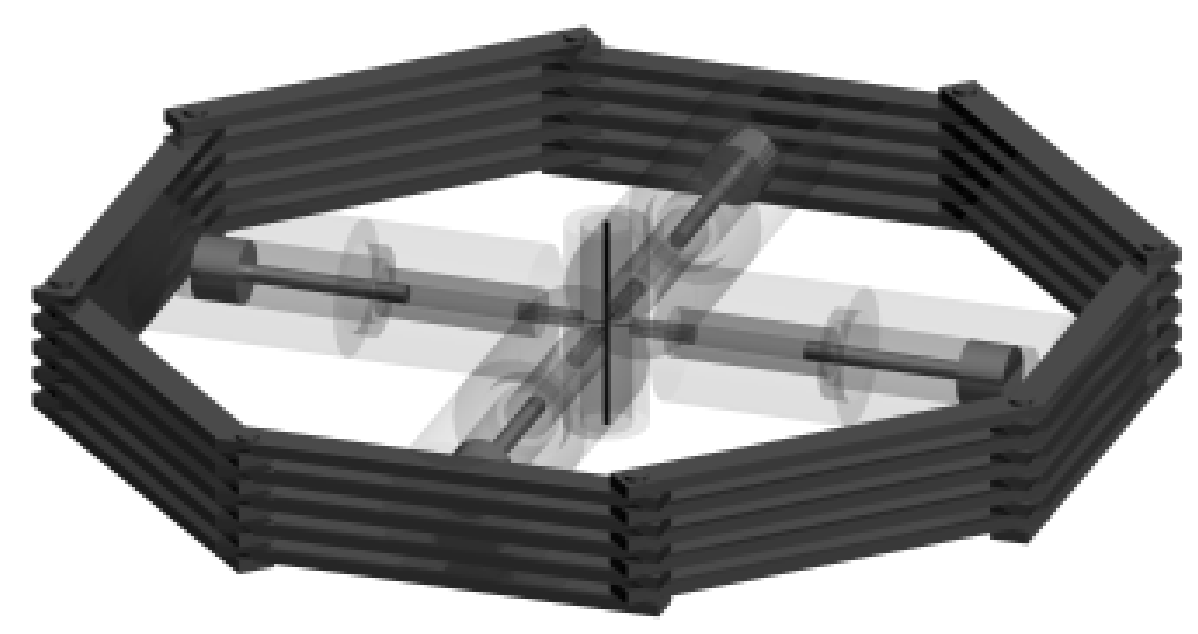

Figure 3. Schematic of a radial array of UHP intensifiers around an axial manifold. The cylindrical end closure at the end of each intensifier simultaneously connects the intensifier gas volume to the manifold and provides a compressive radial stress on the manifold to reduce the stress concentration at the manifold crossbores. The large pressure loads are reacted by an external load frame.

of this region to the nozzle throat and a solenoidal magnet, which in the e-beam energy ad- 
dition scheme surrounds the nozzle at the throat, creates a significant design challenge.

\subsection{Nozzle}

For system integration purposes, the MSHWT nozzle is divided into two regions. An approximately $1 \mathrm{~m}$-long "near nozzle" region includes the portion inside the UHP axial manifold, the throat, the e-beam energy addition region inside the final focusing magnet, and a coupling to the "far nozzle" region. The "far nozzle" region includes the expansion to the MHD augmentation section, the test section, and the exhaust section. This discussion is for the near nozzle region only.

The axially symmetric near nozzle has a throat diameter nominally $3-10 \mathrm{~mm}$ and, for about $10-15 \mathrm{~cm}$ downstream from the throat, critical specifications for the radial profile and surface roughness. The radial profile matches the increase in flow area to the flow density and energy addition to maintain an approximately constant Mach number in the e-beam energy addition region. Unit Reynolds numbers of $\mathrm{O}\left(10^{10} \mathrm{~m}^{-1}\right)$ require the scale of surface imperfections to be $\mathrm{O}(10 \mathrm{~nm})$ to avoid large scale mixing in the boundary layer.

The near nozzle is 1) a $2300 \mathrm{MPa}$ pressure vessel upstream of the throat, 2) a $200 \mathrm{MPa}$ pressure vessel in the energy addition region, 3 ) exposed to a constant temperature boundary condition of about $1200 \mathrm{~K}$ during the flow, 4) exposed to a partial pressure of oxygen of up to $20 \%$ of the total pressure, 5) a diamagnetic element in the $>10 \mathrm{~T}$ magnetic field that contains the e-beam, and 6) an orifice for a flow of air at a density of $0.9 \mathrm{gm} / \mathrm{cm}^{3}$ with a sonic speed of $1800 \mathrm{~m} / \mathrm{s}$. The mass flow rate $(10 \mathrm{~kg} / \mathrm{s}$ of air under these conditions can be compared to $0.5 \mathrm{~kg} / \mathrm{s}$ for a high performance water jet cutter and $20 \mathrm{~kg} / \mathrm{s}$ for a 2.5 " fire hose) and high recovery temperatures result in limited material selection.

\section{NOZZLE}

The MSHWT nozzle provides two significant challenges. The first is the design of the area profile as a function of downstream distance to result in the desired condition at the test section. This is an extraordinarily difficult task that involves the chemistry and physics of reactive flow coupled to a relativistic electron beam absorption in a fully turbulent, three dimensional model and a backwards calculation from the test condition. The approach to this design is described in Anderson, et al. ${ }^{10}$

The second significant challenge is the materials selection and fabrication technology to provide a nozzle that survives the insult of the high pressure-high temperature flow. These materials and fabrication requirements make the near nozzle a high risk element of the MSHWT. The R\&D program is focused on evaluation of existing materials and coating technologies and on component testing of candidate designs and materials. It does not include a materials development program.

\subsection{Nozzle threats}

There is little practical experience with nozzle survivability near the MSHWT operating conditions. Rychkov ${ }^{11}$ describes work at the Russian Academy of Sciences, Siberian Branch, Lavrentyev Institute of Hydrodynamics using the "A-1" device at plenum pressures to about $930 \mathrm{MPa}$ and plenum temperatures of about $1500-2000 \mathrm{~K}$. Conditions in the operating envelope of the MSHWT are at significantly lower stagnation temperatures, but higher stagnation pressures. While it is possible to reproduce the MSHWT pressure and temperatures statically, dynamic testing apparently can be done only using an actual UHP subsystem. In the following discussion of threats to the near nozzle, we separate the attack of the ultra-high pressure, supersonic pressure fluid into three elements: mechanical, thermal, and chemical. The simplest solution is use of a single material in a monolithic design. Layering materials to address specific threats adds to complexity and cost.

\subsubsection{Mechanical threats}

The primary mechanical threat is the shear stress arising from the radial and hoop stresses owing to the ultra-high pressure in the near nozzle region. The pressure in the gas is $2300 \mathrm{MPa}$ in the plenum and decreases to about $650 \mathrm{MPa}$ at the throat, remains about constant at $200 \mathrm{MPa}$ in the energy addition region for $\sim 5 \mathrm{~cm}$ downstream of the throat, 
then decreases rapidly as the flow expands. The first requirement for the nozzle is that it sustain the mechanical stresses generated by the high pressure fluid.

The candidate materials must have a high room temperature strength $(>2000 \mathrm{MPa})$, high oxidation resistance (no significant mass loss during exposures of the order of $100 \mathrm{~s}$ ); no ignitability in a mixture having as much as $20 \%$ oxygen, and moderate ductility $(5-10 \%)$. In this high Reynolds number flow, the "significant mass loss" metric is one that creates a surface roughness greater than about $10 \mathrm{~nm} \mathrm{rms}$. The requirement of a high $(>10 \mathrm{~T})$, uniform magnetic field at the nozzle for the electron beam energy addition places a further systems constraint on the magnetic susceptibility of the material.

Boundary layer-induced shear stresses at the nozzle wall are relatively small (about $4 \mathrm{MPa}$ ) and should not be important unless the wall temperature reduces the metal shear strength to nearly zero. Nevertheless, the erosion of tungsten carbide ( $6 \%$ cobalt binder) nozzles in high pressure $(930 \mathrm{MPa}, 1795 \mathrm{~K})$ nitrogen flows ${ }^{11}$ indicate that mechanical erosion is not well understood.

\subsubsection{Thermal threats}

High nozzle wall temperature both degrades the mechanical properties of the nozzle wall material and enhances chemical reactivity and other thermally activated processes, such as diffusion of helium into the wall and chromium from the bulk to the surface. The thermal degradation of mechanical properties at and near the nozzle surface is serious: $20-80 \%$ lower yield strengths and Young's moduli. Wall temperatures of $1700 \mathrm{~K}$, associated with an air flow at the throat, exceed the superalloy melting temperatures range of 1470-1670 K. The $1000 \mathrm{~K}$ wall temperature associated with a helium cooling fluid is $60-70 \%$ of these temperatures, which raises the issue of creep. Finite element heat transfer calculations indicate flow times of a few tenths of a second are long enough to result in thermal degradation of bulk material properties.

The high thermally-induced stress owing to the temperature gradient from the inside to the outside provides a compressive radial stress that adds to the pressure-induced radial stress to reduce the overall shear stress. However, this stress is proportional to the temperature difference through the nozzle wall, and can be large enough to cause failure in compression (spalling) at the inner nozzle surface if the thermal gradient is too steep. Similar thermally induced stresses result in a requirement to match the coefficients of thermal expansion of layered coatings to avoid delamination.

Surface coatings that provide thermal and chemical barriers between the flow and the structural materials may mitigate some of these threats. However, introduction of helium into the flow immediately upstream of the nozzle throat reduces both the wall recovery temperature and the concentration of oxygen in the boundary layer. Both the development of protective layers and the use of injected helium represent similar increases in system complexity and cost.

\subsubsection{Chemical threats}

The threat posed by high-pressure/hightemperature oxygen is well-known. There appear to be few data for oxidation under high $(>10 \mathrm{MPa})$ oxygen pressures. Costantino ${ }^{12}$ has performed research at $50 \mathrm{MPa}$ pure $\mathrm{O}_{2}$ at approximately $1,200 \mathrm{~K}$ contained in an Inconel X750 alloy pressure vessel, with no apparent reactivity problems. The temperature effect arises from the Arrhenius term $\mathrm{e}^{-(\Delta \mathrm{H} / \mathrm{kT})}$, where the heat of reaction $\Delta H$ is large for the elements making up high performance steels: iron $(\mathrm{Fe}) \quad\left(\mathrm{Fe}_{2} \mathrm{O}_{3}:-197 \mathrm{kcal} / \mathrm{mol} ; \mathrm{Fe}_{3} \mathrm{O}_{4}\right.$ :$267 \mathrm{kcal} / \mathrm{mol}$ ); $\mathrm{Ni}$ (NiO: $-57 \mathrm{kcal} / \mathrm{mol}$ ); $\mathrm{Cr}$ $\left(\mathrm{Cr}_{2} \mathrm{O}_{3}:-273 \mathrm{kcal} / \mathrm{mol}\right)$; molybdenum (Mo) $\left(\mathrm{MoO}_{3}:-178 \mathrm{kcal} / \mathrm{mol}\right)$ and cobalt $(\mathrm{Co})(\mathrm{CoO}:-$ $57 \mathrm{kcal} / \mathrm{mol})$. The driving force for oxidation of metals is the change in the Gibbs Free Energy:

$$
\begin{gathered}
\Delta G=\Delta G^{0}-R T \ln \left[\frac{\left(a_{M}\right)^{x}\left(a_{O_{2}}\right)^{y} 2 /}{a_{M_{x} O_{y}}}\right] \\
\Delta G^{0}=-R T \ln f_{O_{2}}=-R T \ln (\gamma p)
\end{gathered}
$$

where $x \mathrm{M}+(y / 2) \mathrm{O}_{2}=\mathrm{M}_{x} \mathrm{O}_{y}$. The activities, $a$, of the metal and the oxide are sensibly equal to 1 . However, the activity for the nonideal 
gas, high-pressure oxygen cannot be approximated by its pressure but must be described using the fugacity $f$. At equilibrium, $\Delta G=0$ where $\gamma=f / p$ is the fugacity coefficient. Experimental equation of state data for $\mathrm{O}_{2}$ near $400 \mathrm{MPa}$ and $900 \mathrm{~K}$ are not available. However, the similarity of the oxygen and nitrogen EOSs permits approximating oxygen properties using the nitrogen EOS. For nitrogen at $400 \mathrm{MPa}$ and $900 \mathrm{~K}$, the fugacity coefficient is $12.85 .^{13}$ The superalloys generally show a high oxidation resistance at low pressures owing to the formation of $\mathrm{Cr}_{2} \mathrm{O}_{3}$. Even with the use of thermal barrier and diffusion coatings developed for high temperature turbines, the temperature and oxygen exposure (especially under the plausible assumption of an ignition event, such as an off-normal interaction of the e-beam with the nozzle wall) implies a requirement for a dilution of the oxygen content in the boundary layer to below an unknown threshold concentration. Injection of helium immediately upstream of the nozzle throat appears to be required both to reduce the oxygen concentration and to reduce the wall recovery temperature. Other threats, such as nitriding and spalling owing to the helium that diffuses into the nozzle wall are plausible.

Preliminary calculations indicate run timing and synchronization can be adjusted so that a high nickel-chromium-iron alloy nozzle material saturates and allows the magnetic field to stabilize with acceptable strength and uniformity.

\section{NOZZLE SURVIVABILITY EXPERIMENTS}

An R\&D program exists to obtain both practical and scientific information on nozzle survivability. High Reynolds number blowdown experiments ${ }^{14}$ have the objective of exploring the physics and chemistry of flows under conditions similar to those expected in the MSHWT and validating the computational fluid dynamics codes that are critical to wind tunnel performance and analysis. The primary effort is to understand the heat and mass transport properties of the boundary layer and how they affect energy absorption, nozzle wall conditions, boundary layer growth upstream of the MHD section, and electric and magnetic field effects in the MHD section.

UHP subsystem and nozzle component tests under the extreme conditions very near to the MSHWT are under development. An air source, called the "A-2 LITE," will be used to demonstrate most of the critical components of the A-2. The planned performance of the A-2 LITE is:

- Minimum plenum pressure: $2000 \mathrm{MPa}$

- Minimum plenum temperature: $750 \mathrm{~K}$

- Test fluids: $\mathrm{He}, \mathrm{N}_{2}$, air

- Test fluid mass (air): $1.9 \mathrm{~kg}$

In addition to validating the design methodology to be used for the A-2 and the MSHWT, the test matrix for this demonstration experiment includes an assessment of potential nozzle materials and surface roughness. Helium establishes the minimum thermal and mechanical conditions and the effects of gas diffusion into the nozzle wall. Nitrogen establishes both the thermal and mechanical flow conditions for the A-2. Finally, air introduces the chemical threat.

\section{CONCLUSIONS}

A conceptual design for an ultrahigh pressure air source for a hypersonic test facility has been developed. The design provides for high enthalpy, low entropy flows of pure air that, with e-beam and MHD energy addition, offers a broad range of test conditions, including a dynamic pressure of $2000 \mathrm{lbf} / \mathrm{ft}^{2}$ at Mach 15 in a $3 \mathrm{~m}$ diameter test section. The modular construction of UHP intensifiers arrayed radially around an axial manifolds provides arbitrarily long run times beyond the baseline $1 \mathrm{~s}$. The use of proven UHP design methodology and standard materials results in a relatively low risk design.

The nozzle for the wind tunnel is a high risk element in the RDHWT/MARIAH II program. Helium injection into the boundary layer immediately upstream of the nozzle throat reduces both the wall recovery temperature and the concentration of oxygen in contact with the wall. An R\&D program to understand boundary layer mass and heat transport in high Reynolds number flows and to validate CFD models reduces this risk. Ex- 
periments to test directly critical components of the UHP and nozzle subsystems are under construction. While technically demanding, there appear to be no insurmountable barriers to providing a flow of pure air at enthalpies greater than $2500 \mathrm{~kJ} / \mathrm{kg}$ and entropies less than $5 \mathrm{~kJ} / \mathrm{kg}-\mathrm{K}$ for long times.

\section{REFERENCES}

1. Best, J.T., Tirres, C., Fetterhof, T., Crook, R.T., Laster, L., Jordan, J., "RDHWT/MARIAH II Hypersonic Wind Tunnel Program Overview and Requirements," AIAA 2000-2273, 21 ${ }^{\text {st }}$ AIAA Aerodynamic Measurement Technology and Ground Testing Conference, 19-22 June 2000, Denver, CO.

2. Ring, L., Simmons, G., Micheletti, D., Schneider, L., and Costantino, M., "RDHWT/MARIAH II Hypersonic Wind Tunnel Systems Integration Issues," AIAA 2000$2279,21^{\text {st }}$ AIAA Aerodynamic Measurement Technology and Ground Testing Conference, 1922 June 2000, Denver, CO.

3. See, for example, "DoD Aeronautical Test Facilities Assessment," March 1997; and "Hypersonic Test Investment Plan: A Development Plan and Investment Strategy for U.S. Hypersonic Test Capabilities and Facilities," DoD/NASA Study documented in AEDC-TR-94-4, December 1994.

4. Topchiyan, M. \& Kharitonov, A.M., "Wind Tunnels for Hypersonic Study (Achievements, Problems, Outlooks)," The Science Report No. 8-93 of the International Center of Aerophysical Studies, Institute of Theoretical and Applied Mechanics, Russian Academy of Sciences, Siberian Branch, 1993.

5. Meshcheryakov, A.A., Pinakov, V.I., \& Topchiyan, M.E., "Gasdynamic Unit A-1," Report: IGIL SO RAN, Novosibirsk, 1975 (In Russian).

6. Topchiyan, M., (Personal Communication)

7. Topchiyan, M., Valishev, A.I., Rychkov, V.N., Meshcheryakov, A.A., \& Pinakov, V.I, "The Preliminary Study of Ultimate Capabilities of the A-1 Type Facilities With Regard to Stagnation Pressures and Flow Rate/Time," Final Report under Princeton University Contract No. 40665095-M-0190. December 1997.

8. Costantino, M., "A Large Volume $2000 \mathrm{MPa}$ Air Source for the Radiatively Driven Hypersonic Wind Tunnel," $17^{\text {th }}$ International Conference on
High Pressure Science and Technology, July 2530 1999, Honolulu, HI

9. See, for example, Tsiklis, D.S., Handbook of Techniques in High-Pressure Research and Engineering, Plenum Press, New York, NY, 1968; or Manning, W.R.D. and LaBrow, S., High Pressure Engineering, CRC Press, Cleveland, $\mathrm{OH}$, 1971.

10. Anderson, R., Brown, G., \& Miles, R., "Performance Models and predictions for the RDHWT/MARIAH II Hypersonic Wind Tunnel," AIAA 2000-2274, $21^{\text {st }}$ AIAA Aerodynamic Measurement Technology and Ground Testing Conference, 19-22 June 2000, Denver, CO.

11. Rychkov, V., (Personal Communication)

12. Costantino, M., (Unpublished)

13. Lemmon, E.W., Peskin, A.P., McLinden, M.O., \& Friend, D.G., Thermodynamic and Transport properties of Fluids, NIST Standard Reference Database 14 Version 4. National Institute of Standards and Technology. All Equation of State data in this article are from this reference.

14. Raman, K.S., Anderson, R.W., Brown, G.L., Miles, R.B., \& Costantino, M., "An Ultra-High Pressure, Ultra-High Reynolds Number Blowdown Wind Tunnel: Design and Preliminary Experiments," AIAA 2000-0534, $38^{\text {th }}$ AIAA Aerospace Sciences Meeting and Exhibit, January 1013 2000, Reno, NV.

This work was performed under the auspices of the U.S. Department of Energy by University of California Lawrence Livermore National Laboratory under contract No. W-7405-Eng-48. 